\title{
Free Radioiodine
}

National Cancer Institute

\section{Source}

National Cancer Institute. Free Radioiodine. NCI Thesaurus. Code C133759.

Radioactive iodine that is not attached to another molecule. 